\title{
INTRODUCTION
}

\author{
Maria Wincławska*
}

\section{POLITICAL PARTIES AND PARTY SYSTEMS IN THE CONTEMPORARY WORLD}

Political parties evolve in time and adapt to new challenges in the constantly changing environment. Their organization, functions and issues they raise depend on the circumstances created both by the outer world and by the parties themselves. On the one hand, we can observe that parties in the democratic world differ from each other, since they try to fulfil the expectations and requirements of the environment in which they operate. The parties and party systems in new democracies, for example in Mexico, differ from these in the old democracies, for example in the United Kingdom. On the other hand, we also observe that in the modern world challenges the parties face are similar, regardless of where they operate. Among the problems they face worldwide, in some countries more evidently than in others, we find: dropping membership rates, inclusion of women and young people into the organizations, disaffection with well established political parties, rise of radical parties, redefinition of relations between different levels of party organizations in federal, devolved or unitary states, loss of some traditional functions for different organizations, such as social movements or interest groups, and profound changes in communication processes with the public and the media. The parties, however, are not vulnerable. They adapt strategies and tactics to pick up the gauntlet and they change internally.

* Maria Wincławska, Faculty of Political Sciences and International Studies, Nicolaus Copernicus University in Toruń, Poland, mariawin@umk.pl. 